\title{
Use of microbial fuel cells for soil remediation: A preliminary study on DDE
}

The corrections made in this section will be reviewed and approved by a journal production editor.

Domenico Borello ${ }^{\mathrm{a}, \mathrm{b}}$, Gabriele Gagliardia ${ }^{\mathrm{a}}$, Giorgia Aimola ${ }^{\mathrm{b}}$, Valeria Ancona ${ }^{\mathrm{b}, *}$ valeria.ancona@ba.irsa.cnr.it, Paola Grenni ${ }^{c}$, Giuseppe Bagnuolo ${ }^{\mathrm{b}}$, Gian Luigi Garbinic ${ }^{\mathrm{c}}$, Ludovica Rolando ${ }^{\mathrm{c}}$, Anna BarraAnna EaraceioleBarra Caraccioloc

${ }^{a}$ Department of Mechanical and Aerospace Engineering, Sapienza University of Rome, Italy

bational Research Council, Water Research Institute, Bari, Italy

${ }^{\mathbf{c}}$ National Research Council, Water Research Institute, Rome, Italy

* Corresponding author.

\begin{abstract}
DDE (2,2-bis ( $p$-chlorophenyl)-1,1-dichloroetylene) is a very persistent and bioaccumulative pesticide and its residues are continuously found in the environment. Among the green remediation strategies for soil recovery, terrestrial Microbial Fuel Cells (MFC) are arousing great interest in scientific community. MFCs transform energy stored in the chemical bonds of organic compounds into electrical energy thanks to exo-electrogen microorganisms naturally occurring in soil, which catalyse oxidation and reduction reactions in the area between two graphite electrodes. This work reports preliminary data on the use of MFCs for promoting soil decontamination from DDE. Several experimental conditions (e.g. addition of compost and open/closed circuit) were applied for assessing how to improve MFC performance in favouring DDE removal. MFCs promoted a significant DDE removal (39\%) after 2 months, while at the same time any pesticide decrease was observed in the batch condition. Compost addition stimulated microbial activity and improved MFC performance for a longer time.
\end{abstract}

Keywords: MFC; DDE; Bioremediation; Exo-electrogen microorganisms

\section{Introduction}

DDT (1,1,1-trichloro-2,2-bis (4- chlorophenyl) ethane) is an insecticide synthesized in 1873 by an Austrian chemist, Othmar Zeidler, and subsequently rediscovered by the Swiss chemist Paul Hermann Müller during the research of a product suitable to fight lice carriers of typhus. The use of this insecticide was massive in the past because it made it possible the malaria elimination in 1939 (by killing the anopheles mosquito), of the above- 
mentioned typhus and from 1945 the arthropod controls in agriculture [1-5]. DDT is a Persistent Organic Pollutant (POP), and in fact it is currently found in the environment not only as parent compound, but especially in its two main transformation products: DDE (2,2-bis ( $p$-chlorophenyl) -1,1-dichloroetylene) and DDD (1,1dichloro-2,2-bis ( $p$-chlorophenyl) ethane) [2,6]. Although its use as a pesticide has been banned in most of the world countries, large quantities of DDT and its toxic polychlorinated metabolite DDE still persists in soils. DDE is a very persistent and bioaccumulative compound [6,7] and its residues are continuously found in the environment [7-11]. In fact DDE is even more persistent than its parent compound DDT [12].

Several remediation strategies have been proposed to find solutions to the pollution caused by these recalcitrant and ubiquitous molecules; among them, physical-chemical methods have been reported as the best results in a short time [13-16]. However, these methodologies are not only expensive, but can also produce harmful byproducts and move the contamination issue from a specific polluted site to that of waste storage and disposal, in contrast to the principles of Green Remediation [17]. In this context, bioremediation of soil which exploits the natural capability of natural microbial communities in degrading contaminants is in line with the environmental sustainability, rehabilitating ecosystems and giving benefits from both an economic and social point of view [18].

Although the degradative pattern of DDT has been extensively studied, its degradation has not been established in each transformation step, especially regarding DDE. In fact, it can be formed from DDT through several complex reaction pathways: aerobic degradation, abiotic dehydrochlorination and photochemical decomposition $[6,14]$.

Among the most recent "green strategies" developed over the last few decades, bioelectrochemical systems (BES) are promising techniques in promoting environmental bioremediation. BES rely on exo-electrogens microorganisms that have the extracellular electron transport ability. These microorganisms grow in anaerobic condition and catabolite organic compounds, including several contaminants, producing and releasing electrons outside the cell, which are transported through different mechanisms to final acceptors, producing electricity [19, 20]. BES have multiple applications such as: fuel cell (producing electricity), electrolyzer [21], microbial desalination and chemicals production [22]. BES are characterized by two electrodes, anode and cathode, that are connected through an electrical circuit. The anode acts as an electron acceptor and promotes the development of a rich and diversified bacterial community with exo-electrogens microorganisms. The latter can degrade organic molecules in their metabolism, including organic pollutants, generating current and/or secondary products through redox reactions between the anode and cathode [23]. The electrode presence has several advantages: the anode is a permanent and stable electron acceptor, ensuring the oxidation of organic compounds that could be limited by the electron acceptors available in the matrix contained in the BES. The general principle that exo-electrogen bacteria catalyse a reduction reaction at the anode and an oxidation reaction at the cathode has been recognized [24]; however, the bacterial mechanisms which make possible electron exchange with the electrodes have not yet been fully understood [25,26]. BES have been applied successfully for increasing the degradation of many organic pollutants, including highly persistent ones, in laboratory conditions [ 27-36], while field tests are still scarce [37].

There are different types of BESs depending on various factors: the matrix, the type of contaminant and the operational conditions. In particular, the Microbial Fuel Cells (MFCs) have been recently proposed as a bioremediation technology for restoring contaminated soils [20]. MFCs transform energy stored in the chemical bonds of organic compounds (as fuel) into electrical energy thanks to exo-electrogen microorganisms naturally present in the soil, catalyzing oxidation and reduction reactions in the area between two graphite electrodes [20]. It is interesting to note that the MFCs represent a very promising solution as they have the capability to produce 
energy from different wastes [22,38,39]. In typical applications, such as wastewater treatment, the MFC produces energy as long as organic load is present. If the water is pure, no electricity can be generated. This suggests a possible use of MFC as a sensor of contamination [40]. This circumstance, together with the intrinsic simplicity of the MFC structure, makes this solution very interesting for remote, off grid applications, as well as in Developing Countries.

The anode, used as an electron acceptor in anaerobic conditions, promotes the development of a bacterial biofilm around it. The electrons flow from the anode to the cathode through an external circuit, while protons flow through the soil directly to the cathode: here, in aerobic conditions, electrons and protons react with oxygen producing water. Although MFCs are a quite recent technology, they are proving to be innovative with several advantages such as the bioenergy production and for the bioremediation of matrices contaminated by dangerous organic substances. Cao et al. [41] and Guan et al. [42] demonstrated the MFC removal efficiency of hexachlorobenzene (HCB) and Cr (VI). Song and Jiang [43] studied MFC performance using sediments for power generation, bioremediation and sensoring. They analysed several sediment types and observed that the activation time (i.e. the time for reaching maximum power generation) is different depending on the sediment type. The strong concentration of nutrients enhanced cell performance reducing the start-up period and electricity production. A nutrients content of $1-3 \%$ is generally sufficient to produce energy.

Gajda et al. [44] described an interesting concept based on terrestrial MFC using carbon fibre veil as anode, activated carbon as cathode and terracotta as electrolyte. During the cell operation, catholyte was produced close to the cathode. Such catholyte was then successfully used to precipitate heavy metals dispersed in water solutions. Liu et al. [45] demonstrated the capability of MFC in reducing sulphide content (>70\%) and COD $(>54 \%)$ in wastewater, producing up to $2.34 \mathrm{~V}$ and $3.29 \mathrm{~mA}$. Moreover, removal mechanism of sulphide and electric generation in the MFC was further demonstrated by Zhang et al. [46].

Among POPs, the degradation of DDE has never been tested with this technique so far. In this work, terrestrial Microbial Fuel Cells (MFCs) were used to test their effectiveness in promoting DDE degradation in soil, stimulating its dechlorination. In particular, the feasibility and potential of electrical biostimulation through the MFCs was examined. MFCs were set up using DDE spiked soil $(1 \mathrm{mg} / \mathrm{kg})$ under various experimental conditions such as the addition of organic matter (compost) and using an open (OCV) or a close circuit condition $(\mathrm{CCV})$. The pesticide degradation, the electrical outputs and the microbial activity were evaluated over the experimental time.

\section{Materials and methods}

\section{Soil sampling and spiking}

The soil was sampled from the first $30 \mathrm{~cm}$ (surface layer) of an ex-agricultural area located in central Italy. The soil had a neutral $\mathrm{pH}(7), 1.35 \%$ organic carbon and the texture was $28 \%$ sand, $24 \%$ silt and $48 \%$ clay. Organic carbon and $\mathrm{pH}$ (1:2.5 soil-water suspension) were measured following Ancona et al. [47].

A municipal solid waste compost, produced and supplied by Progeva Spa (Laterza (TA), Italy), was mixed (3\%) with the soil used for the experiment. The compost quality was certified on the basis of ISO/IEC 17025, and the main characteristics are shown in previous works [48]. The organic carbon content was $26 \%$.

Soil and compost were air dried and then sieved at $2 \mathrm{~mm}$ to remove stones, gravel and roots. 
About $350 \mathrm{~g}$ of soil were employed for each microcosm (BATCHs or MFCs). The compost was added and mixed (3\%) to half of the soil used for the experiment to stimulate microbial community activity [48].

DDE was purchased from Sigma-Aldrich and used to prepare the stock solution in acetone (HPLC Plus, for HPLC, GC, and residue analysis, $\geq 99.9 \%$ purity, Sigma Aldrich). Aliquots of distilled water and calculated quantity of stock solution were prepared to obtain a final DDE expected concentration of $1 \mathrm{mg} / \mathrm{kg}$ for each microcosm (batches or MFCs). The spike-solution was poured drop by drop, covering the entire surface of the soil. Each contaminated soil was put in closed glass containers and vigorously mixed overnight on a roller mixer. This procedure assured the best DDE mixing to soil.

\section{MFC and BATCH setup}

Several operational conditions have been recently proposed aiming at maximizing the electricity yields (or the reduction of organic contents) of the MFC by changing materials for the anode, cathode, catalyzers, electrolytes etc. [22]. For example, in Papaharalabos et al. [49] shape and material of a MFC were optimized to maximize COD reduction and electricity yields. Positive results were obtained but they were case-specific, and no definite guidelines were obtained.

In this work, the main aim was to test the MFC as a strategy for bioremediation of soils contaminated with persistent organic pollutants. Consequently, a single chamber MFC with a simplified configuration was used. The MFC consists in a single chamber with inert, and graphite-based electrodes (anode and cathode); graphite is an appropriate conductor and an easily available material. The soil used, having its own electrical conductivity, acts as an electrolyte for the movement of hydrogen ions to the cathode, as well as providing both the bacterial community and the nutrients existing naturally in the matrix. The soil (ca. $350 \mathrm{~g}$ in each MFC) was adequately prepared and completely saturated in order to obtain anaerobic conditions. In fact, the water content (WC) is a key factor for the MFC performance because it regulates the chemical processes [50] underling this technology. It is very important that the WC in a terrestrial MFC is maintained quite constant and above a threshold value (estimated around 24\%), which makes it possible the cell to operate at a full capacity, guarantying energy production. Beyond this point, the energy generation increases as the water content increases and this trend continues until the soil reaches, or slightly exceeds, its field capacity. Because the saturation threshold can vary according to the composition of the soil, in this work a threshold of $30 \%$ was adopted.

A soil layer $(1 \mathrm{~cm})$ was packed into the bottom of each MFC. Then, an anode was placed on the top of the soil and after that, each container was filled with other soil (at least $5 \mathrm{~cm}$ ). After any step of this procedure, soil and anode were squished so forming a smooth layer and removing air bubbles. The cathode was then placed on the top of the soil and was exposed to air. This type of MFC does not require the use of semipermeable membranes because in this cell, aerobic microbes, naturally present in the soil, would act as a filter, consuming oxygen and preventing infiltration into the anodic compartment. Each anode and cathode were then connected each other with an external circuit to make the electron movement possible. The MFCs were set up by adopting different experimental conditions. Moreover, soil samples with the same treatments as for MFCs were prepared for BATCH condition (Table 1) and used as controls. BATCHs consisted of closed glass beakers (1 L). MFCs and BATCHES were put in the dark. 
The table layout displayed in this section is not how it will appear in the final version. The representation below is solely purposed for providing corrections to the table. To preview the actual presentation of the table, please view the Proof.

Experimental set up in MFC and BATCH conditions.

\begin{tabular}{|c|c|c|c|}
\hline \multicolumn{2}{|c|}{ Classification } & Materials & Voltage condition \\
\hline \multirow{6}{*}{ MFC } & Soil & Soil & Open circuit \\
\hline & Soil + compost & Soil with compost addition & Open circuit \\
\hline & Soil + DDE (ocv) & Soil spiked with DDE & Open circuit \\
\hline & Soil $+D D E(c c v)$ & Soil spiked with DDE & Closed circuit \\
\hline & Soil + DDE + compost (ocv) & Soil spiked with DDE and compost addition & Open circuit \\
\hline & Soil + DDE + compost $(c c v)$ & Soil spiked with DDE and compost addition & Closed circuit \\
\hline \multirow{4}{*}{ Batch } & Soil & Soil & - \\
\hline & Soil + compost & Soil with compost addition & - \\
\hline & Soil $+D D E$ & Soil spiked with DDE & - \\
\hline & Soil + DDE + compost & Soil spiked with DDE and compost addition & - \\
\hline
\end{tabular}

Soil samples were collected (0 day) from each different conditioned soil just before their input in the MFCs or BATCHES for evaluating any possible acute effect of DDE and or compost addition on the microbial number, viability and activity. After the initial soil characterization, at selected times (2, 6 and 12 months), the electrical measurements, chemical and microbiological analyses were performed. Each sampling was destructive and two MFCs for each condition were sacrificed.

\section{Electrical measurements}

Fuel cells are energy conversion systems which directly convert the chemical energy stored in a fuel in electric energy without any intermediate combustion process. The main advantage is the higher theoretical efficiency when compared to thermal cycles, that are affected by the Carnot limit. However, in real cases limited ions diffusion through the electrolyte (here the soil) affects the electric efficiency of this technology.

The basic scheme of a MFC is described in Fig. 1.

alt-text: Fig. 1

Fig. 1 
- Last 6 months: a measurement station (see

- Fig. 2) was designed and realized to perform measurements. The station was able to modulate the operating conditions switching between open and closed-circuit conditions, varying the resistance and modulating the charge (open circuit) and discharge (closed circuit) period. Resistance values analysed were 100, 200, 500, 1000, 2000, 5000 and 10,000 Ohm. Charge and discharge periods are set equal to $900 \mathrm{~s}$ and $15 \mathrm{~s}$ respectively.

\section{Water content in soil}

At each sampling time in all experimental conditions, soil samples were collected to evaluate moisture content through direct measurement. About $10 \mathrm{~g}$ of fresh soil were placed in oven at $105^{\circ} \mathrm{C}$ for $24 \mathrm{~h}$. Then dry soils were immediately weighed at $3 \mathrm{~h}$ intervals until the weight was stable (Method II.2 "Gravimetric determination of the moisture content" of the Italian Decree September 13, 1999).

\section{Chemical analyses of DDE}

A DDE extraction method was developed for this experiment. Soil samples (ca $300 \mathrm{~g}$ from each MFC or BATCH) were dried at $30{ }^{\circ} \mathrm{C}$ for 3 days. The soil granulometry was decreased by chopping it gently. The samples were then divided in three (soil with compost) or two (soil without compost) aliquots and weighed. Three ultrasonic extraction cycles were carried out for $20 \mathrm{~min}$ for each aliquot, using an extraction solvent (hexane: acetone 1:1). Each extract was placed in an evaporating flask and make up to a volume of about $5 \mathrm{~mL}$ with a RotaVapor at $30^{\circ} \mathrm{C}$.

A purification step using an ASE 350 Dionex was then made with hexane as a solvent and using neutral silica and acid silica in a ratio of 1:4. The purification method was the following: the preheat temperature was $100{ }^{\circ} \mathrm{C}$ for $5 \mathrm{~min}$, the heat temperature was $100{ }^{\circ} \mathrm{C}$ for $5 \mathrm{~min}$, the static time was $5 \mathrm{~min}$ for 4 cycles, volume flush $80 \%$ and purge $60 \mathrm{~s}$, pressure $1500 \mathrm{psi}$.

Finally, each resulting sample was made up to $200 \mathrm{~mL}$ and placed in a glass flask. The extracted samples were analysed in GC-MS Thermo Polaris Q. The analytical conditions were: the injector temperature of the oven was $270{ }^{\circ} \mathrm{C}$ in splitless mode for $2 \mathrm{~min}$; the carrier flow gas $\mathrm{He}$ was at $1.4 \mathrm{~mL} / \mathrm{min}$; the initial oven temperature was $75{ }^{\circ} \mathrm{C}$ for $2 \mathrm{~min}$; the first ramp was from $20^{\circ} \mathrm{C} / \mathrm{min}$ to $150{ }^{\circ} \mathrm{C}$ for $2 \mathrm{~min}$, the second ramp was at $3{ }^{\circ} \mathrm{C} / \mathrm{min}$ to $260{ }^{\circ} \mathrm{C}$ for $2 \mathrm{~min}$ and the third ramp was at $20^{\circ} \mathrm{C} / \mathrm{min}$ to $300{ }^{\circ} \mathrm{C}$ remaining $1 \mathrm{~min}$. The injection volume was $1 \mu \mathrm{L}$. An Agilent VF- $5 \mathrm{~ms}$ column was used $(30 \mathrm{~m} \times 0.25 \mathrm{~mm}$ ID, DF $0.25 \mu \mathrm{m})$. For the Mass-spectrometer the MS/MS method was the following: start time 9 min and dumping gas flow $2 \mathrm{~mL} / \mathrm{min}$. The DDE precursor ion was 318.0 and the product ions were $245.0-250.0$. The internal standard $194 \mathrm{C} 13$ the precursor ion was 440.0 and the product ions were 400.0-408.0.

\section{Soil microbial community analyses}

Microbiological analyses (Microbial abundance, Cell viability and Microbial activity) were performed at the start of the experiment before the MFC and BATCHES set up (day 0) and at 2, 6 and 12 months. The Total microbial abundance (No. cell/g soil) was performed using the direct count method with DAPI (4',6-diamidino-2phenylindole) as the fluorescent intercalant of DNA. Two sub-samples (1 g) from each replicate were collected and fixed with a sterilized phosphate buffer solution with $2 \%$ formaldehyde and $0.5 \%$ Tween 20 . After shaking, the suspension was left for $24 \mathrm{~h}$ to allow larger particles to settle out. A DAPI solution was added to an aliquot of supernatant and put in contact for $15 \mathrm{~min}$ in the dark at $4{ }^{\circ} \mathrm{C}$. The solution was then filtered through a $0.2 \mu \mathrm{m}$ 
polycarbonate filter. The microbial cells were counted under a Leica DM 4000 B fluorescence microscope (Leica Microsystems GmbH, Wetzlar, Germany) [51].

Cell viability (\% live cells/live + dead) was evaluated in two fresh soil sub-samples $(1 \mathrm{~g}$ each) from each replicate, in accordance to previous works [52,53]. The fluorescent dyes used were the SYBR Green II and Propidium Iodide (Sigma-Aldrich, Germany). This method exploits the different size and capability of these molecules to pass through membrane cell: SYBR Green II is small so it can enter inside each live cell, while propidium iodide is bigger and can only enter in dead or damaged cells. Thanks to this difference, it was possible to distinguish viable (green) and dead (red) cells under a fluorescence microscope (Leica DM 4000 B fluorescence microscope, Leica Microsystems GmbH, Wetzlar, Germany) [51,53].

Finally, the microbial activity was measured as dehydrogenase activity, which reflects the overall microbial respiration rate and therefore the biological oxidation of organic matter [52,54]. The applied method is based on extraction and colorimetric determination of the intensely coloured 2,3,5-triphenyl formazan (TPF) produced from the reduction of the colourless 2,3,5-triphenyltetrazoliumchloride (TTC) in soil samples $24 \mathrm{~h}$ after an incubation at $37^{\circ} \mathrm{C}$ in the dark [52,54]. Soil dehydrogenase activity was expressed as $\mu \mathrm{g} T \mathrm{TF} / \mathrm{g}$ dry soil and was measured with a Thermo Multiskan FC Microplate Photometer (Thermo Fisher Scientific; Waltham, MA, USA).

\section{Statistical analysis}

Both the chemical and the microbiological results at each sampling time are expressed as means \pm standard errors (SE) of two values from each replicate microcosm. Data were analysed using the SIGMASTAT software. Analysis of variance (one-way analysis of variance) was used to assess the significant differences in DDE concentration, dehydrogenase activity, total microbial abundance among the various conditions. The $p$-values $<0.05$ were considered statistically significant.

\section{Results}

\section{Voltage and power generation}

The electrical characteristics, such as voltage and power generation were measured for a total period of 12 months. However, at month 2 and 6, two of the replicates were opened for biological and chemical tests.

As specified above, the measuring station was available only after the 6th month. It is then useful to split the discussion in two intervals: from 0 to 6 th month and from 6 th to 12 th month.

The open circuit voltage and the power produced in the first period are shown in Fig. 3. It is possible to see that, in open circuit conditions, the voltage showed a certain modulation around average conditions. This could be related to the environmental conditions and/or other external parameters. Interestingly, in this initial period, compost did not seem to give an added value. While the Soil + Compost + DDE cell required about 20 days before starting to produce energy, the Soil $+D D E$ cell immediately worked, thus indicating a more suitable microbial composition [43]. 

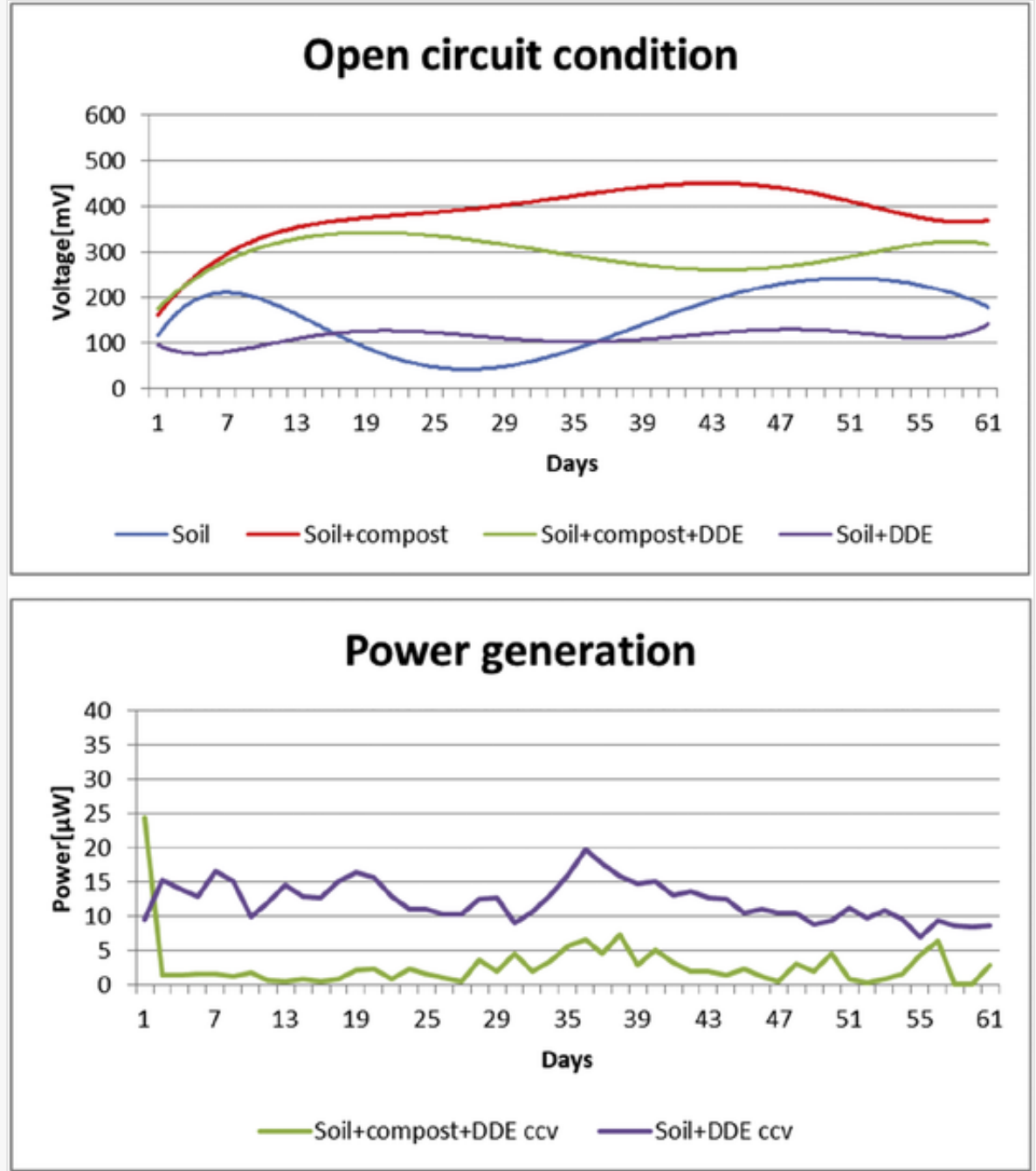

Electrical measurements in the first 6 months: up-voltage; down: power generation.

Unfortunately, the second replicate (i.e. the one opened at 6th month) did not work properly and the produced energy rapidly went to zero after 2.5 months (see Fig. 4).

alt-text: Fig. 4

\section{Fig. 4}

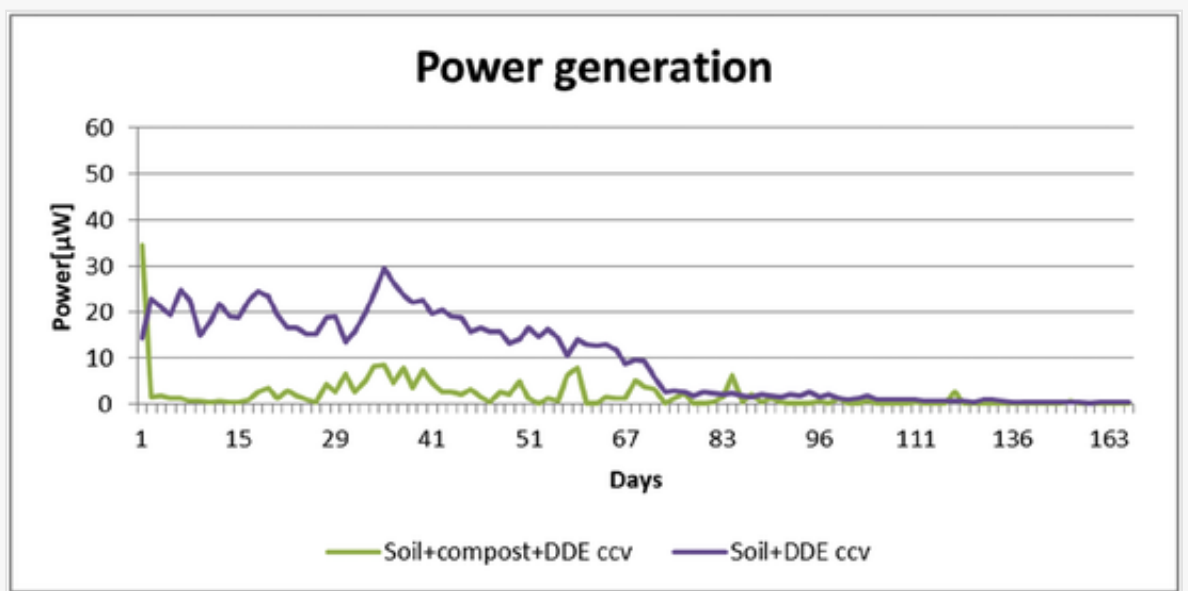


In the second test time interval, in addition to recording the voltage in open circuit condition, power curves were performed daily in each sample by applying the procedure described in $\$ 2.2$, in order to monitor the energy potential of this technology over time. Thus, during this time, the closed-circuit condition was considered for all the samples. Therefore, in the following plots, the distinction between cells under open and closed conditions no longer exists. The cells in which DDE was present, are named using a number next to each condition. Fig. 5 depicts the behaviour of the voltage of the samples in open circuit condition.

alt-text: Fig. 5

\section{Fig. 5}

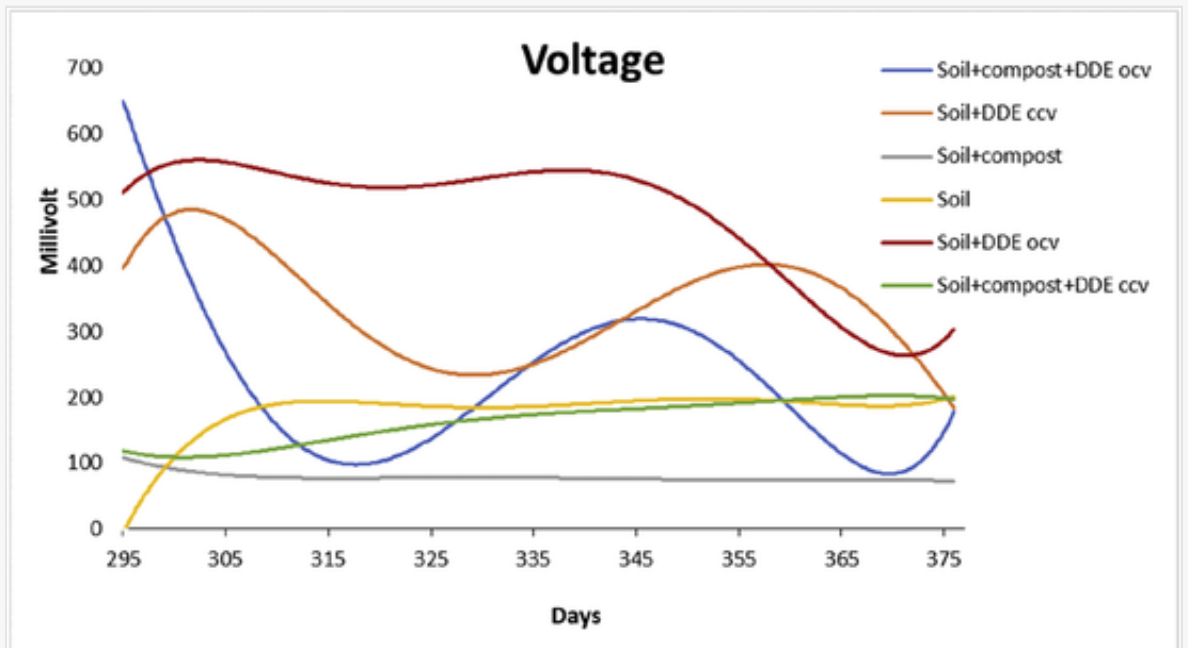

Daily voltage measurements of microbial fuel cells for months 6-12.

The fuel cells containing only DDE still show the highest performance. In fact, they properly work up to the end while the Soil $+D D E+$ compost cells show an unstable behaviour. The maximum voltage obtained was of $540 \mathrm{mV}$. The shortage of raw material is the responsible for the low voltage value obtained for the Soil and Soil + compost MFCs.

Due to the availability of accurate measurements at different resistance, polarization curves were plotted using monthly average data collection. Fig. 6 shows the power generation (continuous line) and current (dashed line) obtained using the Ohm's law under varying resistances. The 3 pictures make reference to the periods: A) days 285-315; B) 315-345; C) 345-375. 

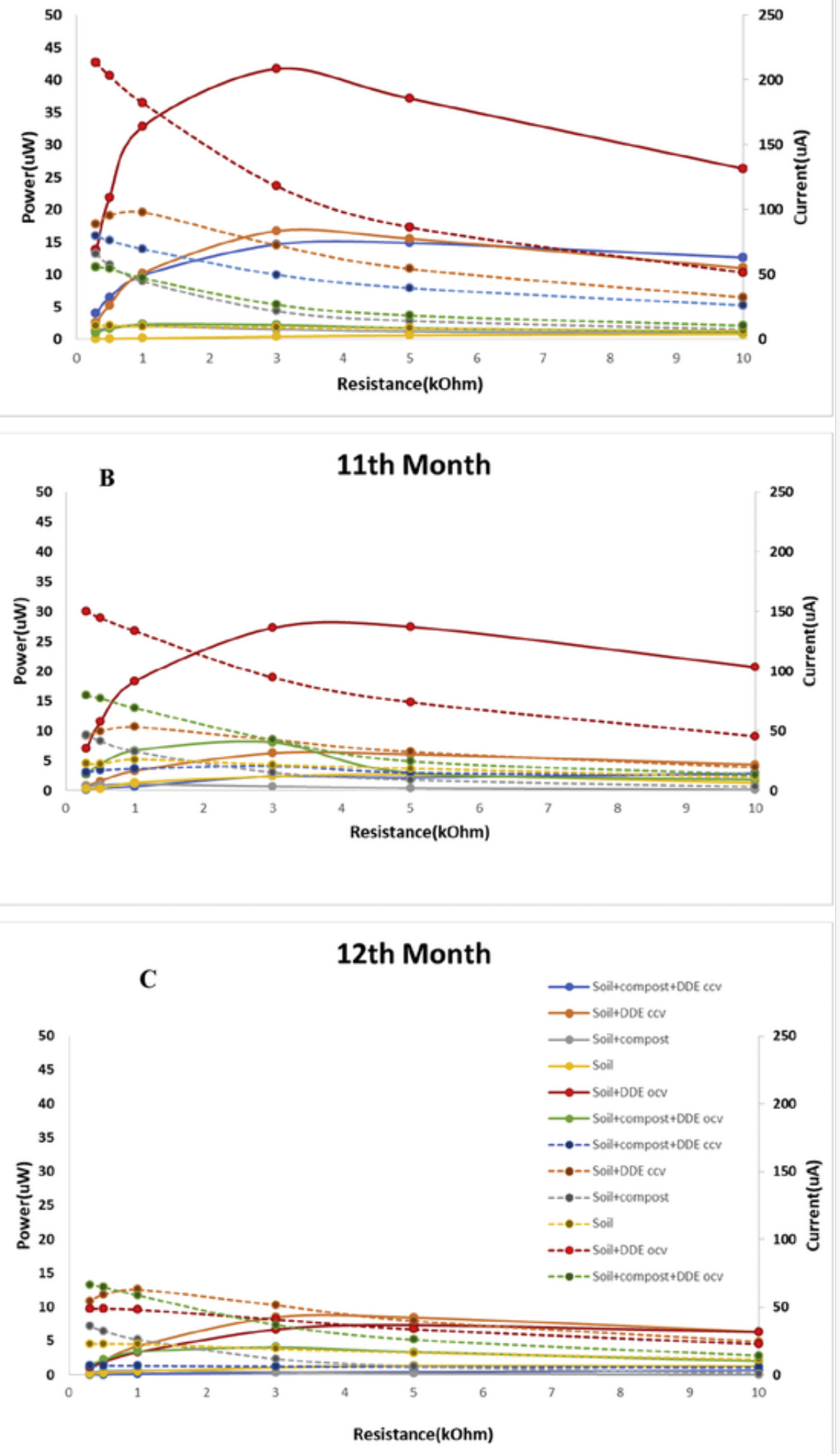
The trend observed in the first months remained unchanged over the time: cells with DDE exhibited the best performance. The maximum power output was $55 \mu \mathrm{W}$, registered in the second week of the 10th month of testing. Observing the trend over the months, a first decrease was noticed during the second half of the 11th month where the maximum value registered was almost $30 \mu \mathrm{W}$, followed by a total collapse in the last month, even falling down below $5 \mu \mathrm{W}$.

\section{Water content in soil}

In Tables 2 and 3 the results of soil water content analyses are reported. In all MFC conditions water content drastically reduced at the end of the experiment, with the lowest value in MFCs spiked with DDE $(18.0 \pm 0.2 \%)$. Differently, in all the BATCH samples, water content remained constant over the 12-month experiment.

alt-text: Table 2

Table 2

Average values ( \pm standard error, s.e.) of DDE removal (\%), Total microbial abundance, Cell viability, Dehydrogenase activity Water content in soils sampled at different times of investigation $(0,2,6,12$ months) in MFCs and Batch samples (n.d. $=$ not detected).

\begin{tabular}{|c|c|c|c|c|c|c|c|}
\hline \multicolumn{2}{|c|}{ Sample } & \multirow{2}{*}{$\begin{array}{l}\begin{array}{l}\text { Time } \\
\text { (months) }\end{array} \\
0\end{array}$} & \multirow{2}{*}{$\begin{array}{l}\text { DDE } \\
\text { Removal } \\
(\%) \\
- \\
\end{array}$} & \multirow{2}{*}{$\begin{array}{l}\begin{array}{l}\text { Total abundance } \mathbf{~} \\
\text { cells } \mathbf{g}^{-1} \pm \text { s.e. }\end{array} \\
4.6 \times 10^{7} \pm 1.7 \times 10^{6}\end{array}$} & \multirow{2}{*}{$\begin{array}{l}\text { Cell } \\
\text { viability } \\
\% \pm \text { s.e. } \\
66.8 \pm 1.1\end{array}$} & \multirow{2}{*}{ 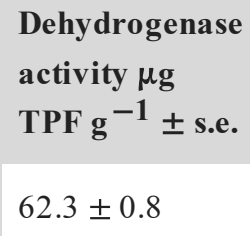 } & \multirow{2}{*}{$\begin{array}{l}\begin{array}{l}\text { Water } \\
\text { content } \\
(\%) \pm \mathrm{s}\end{array} \\
32.8 \pm(\end{array}$} \\
\hline MFC & & & & & & & \\
\hline & \multirow{3}{*}{ Soil + DDE $(o c v)$} & 2 & $39.4 \pm 4.0$ & $7.4 \times 10^{7} \pm 3.6 \times 10^{6}$ & $46.2 \pm 4.0$ & $145.3 \pm 85.9$ & $29.9 \pm c$ \\
\hline & & 6 & $32.0 \pm 3.2$ & $2.1 \times 10^{8} \pm 4.0 \times 10^{6}$ & $72.1 \pm 4.3$ & $92.3 \pm 1.6$ & $25.3 \pm c$ \\
\hline & & 12 & $35.7 \pm 3.5$ & $1.2 \times 10^{7} \pm 2.1 \times 10^{6}$ & $31.4 \pm 2.0$ & $15.3 \pm 3.0$ & $18.5 \pm c$ \\
\hline & \multirow{4}{*}{ Soil + DDE $(c c v)$} & 0 & - & $4.6 \times 10^{7} \pm 1.7 \times 10^{6}$ & $66.8 \pm 1.1$ & $62.3 \pm 0.8$ & $32.8 \pm c$ \\
\hline & & 2 & $38.0 \pm 1.8$ & $8.8 \times 10^{7} \pm 6.1 \times 10^{6}$ & $51.3 \pm 2.5$ & $103.4 \pm 36.6$ & $28.4 \pm c$ \\
\hline & & 6 & n.d & $2.2 \times 10^{8} \pm 2.2 \times 10^{6}$ & $72.5 \pm 2.1$ & $133.3 \pm 62.3$ & $27.0 \pm c$ \\
\hline & & 12 & n.d. & $9.9 \times 10^{6} \pm 6.08 \times 10^{5}$ & $51.4 \pm 0.3$ & $19.3 \pm 2.1$ & $18.4 \pm c$ \\
\hline & \multirow{4}{*}{$\begin{array}{l}\text { Soil + DDE + compost } \\
(\text { ocv })\end{array}$} & 0 & - & $1.4 \times 10^{8} \pm 1.2 \times 10^{7}$ & $61.4 \pm 0.1$ & $207.0 \pm 24.3$ & $34.4 \pm c$ \\
\hline & & 2 & $25.6 \pm 3.0$ & $1.2 \times 10^{8} \pm 1.8 \times 10^{7}$ & $71.8 \pm 3.8$ & $116.0 \pm 10.8$ & $32.0 \pm c$ \\
\hline & & 6 & $30.4 \pm 2.0$ & $8.1 \times 10^{7} \pm 7.7 \times 10^{6}$ & $25.0 \pm 1.4$ & $48.2 \pm 4.8$ & $33.4 \pm c$ \\
\hline & & 12 & $46.6 \pm 1.0$ & $4.1 \times 10^{6} \pm 4.6 \times 10^{5}$ & $49.5 \pm 0.8$ & $34.7 \pm 2.4$ & $17.6 \pm c$ \\
\hline & \multirow{2}{*}{$\begin{array}{l}\text { Soil + DDE + compost } \\
(c c v)\end{array}$} & 0 & - & $1.4 \times 10^{8} \pm 1.2 \times 10^{7}$ & $61.4 \pm 0.1$ & $207.0 \pm 24.3$ & $34.4 \pm c$ \\
\hline & & 2 & $31.3 \pm 1.0$ & $1.3 \times 10^{8} \pm 2.0 \times 10^{7}$ & $53.2 \pm 1.5$ & $123.9 \pm 12.1$ & $33.8 \pm c$ \\
\hline
\end{tabular}




\begin{tabular}{|c|c|c|c|c|c|c|c|}
\hline & & 6 & $33.0 \pm 2.0$ & $1.8 \times 10^{8} \pm 1.8 \times 10^{7}$ & $55.8 \pm 0.2$ & $15.0 \pm 11.9$ & $29.1 \pm c$ \\
\hline & & 12 & $34.7 \pm 3.0$ & $3.0 \times 10^{7} \pm 2.6 \times 10^{6}$ & $49.7 \pm 0.8$ & $19.2 \pm 11.9$ & $21.9 \pm c$ \\
\hline \multirow{8}{*}{ Batch } & \multirow{4}{*}{ Soil + DDE } & 0 & - & $4.6 \times 10^{7} \pm 1.7 \times 10^{6}$ & $66.8 \pm 1.1$ & $62.3 \pm 0.8$ & $32.8 \pm c$ \\
\hline & & 2 & $0 \pm 0.1$ & $8.8 \times 10^{7} \pm 2.8 \times 10^{6}$ & $45.4 \pm 2.0$ & $73.7 \pm 14.2$ & $32.0 \pm c$ \\
\hline & & 6 & $0 \pm 0.1$ & $1.4 \times 10^{8} \pm 3.1 \times 10^{6}$ & $67.2 \pm 1.2$ & $16.9 \pm 1.1$ & $32.4 \pm c$ \\
\hline & & 12 & $60.9 \pm 8.2$ & $1.0 \times 10^{8} \pm 1.6 \times 10^{7}$ & $22.3 \pm 6.9$ & $47.9 \pm 28.5$ & $32.3 \pm c$ \\
\hline & \multirow{4}{*}{ Soil + DDE + compost } & 0 & - & $1.4 \times 10^{8} \pm 1.2 \times 10^{7}$ & $61.4 \pm 0.1$ & $207.0 \pm 24.3$ & $34.4 \pm c$ \\
\hline & & 2 & $0 \pm 0.1$ & $1.4 \times 10^{8} \pm 2.7 \times 10^{6}$ & $54.3 \pm 1.7$ & $364.4 \pm 112.0$ & $33.4 \pm c$ \\
\hline & & 6 & $0 \pm 0.1$ & $4.7 \times 10^{8} \pm 2.8 \times 10^{7}$ & $53.8 \pm 0.7$ & $23.0 \pm 2.5$ & $33.4 \pm c$ \\
\hline & & 12 & $65.6 \pm 8.0$ & $2.1 \times 10^{7} \pm 2.7 \times 10^{7}$ & $17.6 \pm 6.2$ & $115.9 \pm 7.8$ & $33.9 \pm c$ \\
\hline
\end{tabular}

\section{alt-text: Table 3}

Table 3

(i) The table layout displayed in this section is not how it will appear in the final version. The representation below is solely purposed for providing corrections to the table. To preview the actual presentation of the table, please view the Proof.

Average values ( \pm standard error, s.e.) of Total microbial abundance, Cell viability, Dehydrogenase activity and Water content in soils sampled at different times of investigation (0, 2, 6, 12 months) in MFCs and Batch samples set up without DDE.

\begin{tabular}{|c|c|c|c|c|c|c|}
\hline \multicolumn{2}{|c|}{ Sample } & \multirow{2}{*}{$\begin{array}{l}\text { Time } \\
\text { (months) }\end{array}$} & \multirow{2}{*}{$\begin{array}{l}\text { Total abundance } \mathbf{N} \\
\text { cells } \mathbf{g}^{-1} \pm \text { s.e. } \\
7.7 \times 10^{7} \pm 6.8 \times 10^{6}\end{array}$} & \multirow{2}{*}{$\begin{array}{l}\text { Cell } \\
\text { viability } \\
\% \pm \text { s.e. } \\
72.8 \pm 2.1\end{array}$} & \multirow{2}{*}{$\begin{array}{l}\text { Dehydrogenase activity } \\
\mu \mathrm{g} \text { TPF } \mathrm{g}^{-1} \pm \text { s.e. } \\
87.7 \pm 0.1\end{array}$} & \multirow{2}{*}{$\begin{array}{l}\text { Water content } \\
(\%) \pm \text { s.e. } \\
33.1 \pm 0.06\end{array}$} \\
\hline \multirow{8}{*}{ MFC } & \multirow{4}{*}{ Soil } & & & & & \\
\hline & & 2 & $1.2 \times 10^{8} \pm 9.9 \times 10^{6}$ & $45.6 \pm 6.4$ & $209.3 \pm 37.3$ & $30.1 \pm 0.05$ \\
\hline & & 6 & $1.4 \times 10^{8} \pm 3.4 \times 10^{7}$ & $58.0 \pm 5.2$ & $35.8 \pm 3.27$ & $27.9 \pm 0.57$ \\
\hline & & 12 & $3.0 \times 10^{7} \pm 2.9 \times 10^{5}$ & $32.2 \pm 2.0$ & $16.8 \pm 4.9$ & $21.2 \pm 0.01$ \\
\hline & \multirow{4}{*}{ Soil + compost } & 0 & $1.1 \times 10^{8} \pm 6.2 \times 10^{6}$ & $74.7 \pm 0.6$ & $89.2 \pm 8.9$ & $34.4 \pm 0.01$ \\
\hline & & 2 & $8.0 \times 10^{7} \pm 8.0 \times 10^{6}$ & $58.0 \pm 4.1$ & $295.3 \pm 48.0$ & $30.8 \pm 0.12$ \\
\hline & & 6 & $3.5 \times 10^{8} \pm 8.2 \times 10^{6}$ & $56.9 \pm 1.2$ & $18.8 \pm 4.6$ & $26.8 \pm 0.35$ \\
\hline & & 12 & $4.2 \times 10^{7} \pm 2.0 \times 10^{6}$ & $41.4 \pm 3.3$ & $27.1 \pm 5.7$ & $20.9 \pm 0.18$ \\
\hline \multirow[t]{5}{*}{ Batch } & \multirow{4}{*}{ Soil } & 0 & $7.7 \times 10^{7} \pm 6.8 \times 10^{6}$ & $72.8 \pm 2.1$ & $87.7 \pm 0.1$ & $33.1 \pm 0.06$ \\
\hline & & 2 & $1.0 \times 10^{8} \pm 7.3 \times 10^{6}$ & $44.1 \pm 2.0$ & $214.9 \pm 52.1$ & $32.9 \pm 0.00$ \\
\hline & & 6 & $1.6 \times 10^{8} \pm 9.9 \times 10^{6}$ & $50.1 \pm 1.1$ & $15.3 \pm 0.35$ & $31.8 \pm 0.32$ \\
\hline & & 12 & $1.6 \times 10^{8} \pm 4.8 \times 10^{6}$ & $41.6 \pm 1.3$ & $58.2 \pm 8.0$ & $30.3 \pm 0.06$ \\
\hline & Soil + compost & 0 & $1.1 \times 10^{8} \pm 6.2 \times 10^{6}$ & $74.7 \pm 0.6$ & $89.2 \pm 8.9$ & $34.4 \pm 0.01$ \\
\hline
\end{tabular}




\begin{tabular}{|l|l|l|l|l|}
\hline 2 & $7.9 \times 10^{7} \pm 2.6 \times 10^{6}$ & $63.5 \pm 6.2$ & $297.4 \pm 21.0$ & $33.4 \pm 0.17$ \\
\hline 6 & $2.7 \times 10^{8} \pm 1.9 \times 10^{7}$ & $36.3 \pm 1.6$ & $12.6 \pm 0.64$ & $33.4 \pm 0.37$ \\
\hline 12 & $1.5 \times 10^{8} \pm 3.1 \times 10^{7}$ & $30.1 \pm 3.5$ & $69.3 \pm 9.1$ & $33.8 \pm 0.26$ \\
\hline
\end{tabular}

\section{DDE assessment}

The results of DDE analysis (expressed as removal percentage: \%) are reported in Table 2.

At 2 months the average DDE removal in Soil $+D D E$ MFCs was 38.7\% (value calculated between ocv and $c c v$ conditions) while in Soil $+D D E+$ compost MFCs the average (ocv and $c c v$ ), pesticide removal was $28.45 \%$. In the subsequent sampling (6 months), just a further slight decrease in pesticide removal (ca $3 \%$ ) was observed and only in presence of compost. Unfortunately, because the Soil + DDE (ccv) MFCs did not work properly $(\S 3.2)$ they were not considered for the successive chemical analysis. DDE concentrations measured in Soil $+D D E(o c v)$ MFCs were not significantly different from those found at 2 months. This suggests that DDE degradation stopped at this time in this condition.

On the other hand, in BATCH samples no decrease in DDE was observed.

The chemical analysis performed 1 year from the start of the experiment showed that DDE did not further decrease in Soil $+D D E$ MFCs, while a slight reduction was observed in Soil $+D D E+$ compost MFCs where the final average removal was $40.65 \%$. In BATCH conditions a removal of DDE $(60 \%)$ was observed only at this time (Table 2).

\section{Microbial abundance, cell viability and dehydrogenase activity}

The microbial abundance, cell viability, and dehydrogenase activity of the MFC and BATCH soils, at different time of investigation (0, 2, 6, 12 months), are reported in Tables 2 and 3. An initial detrimental effect (day 0) was observed on the soil microbial community after adding DDE; in fact, the microbial abundance, cell viability and dehydrogenase activity values were significantly lower in DDE-treated soils if compared to the corresponding un-treated ones.

In Soil $+D D E+$ compost MFCs, the initial microbial abundance values were higher than in the other conditions in line with adding bacteria with compost inputs; then the microbial abundances decreased with the lowest values at the end of the experiment. Interestingly, in the MFC set up without DDE (Table 3), the microbial abundances were higher than those found the presence of the pesticide, suggesting a detrimental effect of this chemical on the microorganisms. However, the number of bacterial cells diminished drastically at 12 months (Table 3). In BATCH samples both in presence/absence of DDE and/or compost the highest microbial abundance values were observed at the end of experiment (Table 3 ).

The average values of Cell viability were higher in Soil $+D D E$ MFCs than in the other conditions until month 6 (Tables 2 and 3). The values decreased in all conditions at the end of the experiment.

Finally, the microbial activity, measured as dehydrogenase activity, was quite high in all MFC conditions until month 6, with average values of $107 \mu \mathrm{g}$ TPF $\mathrm{g}^{-1}$ and $102 \mathrm{TPF} \mathrm{g}^{-1}$ in Soil + DDE and Soil $+D D E+$ compost, respectively. In the BATCH conditions, the highest values were found in compost presence. At 12 months, the microbial activity values were quite high in both BATCH conditions. 
DDE transformation requires complex pathways and it can also occur in anaerobic conditions [55-57]. The measurements of MFCs performed at 60 days showed a good electrical performance and DDE removal, in particular in the Soil $+D D E$ MFCs. These results can be ascribed to the bacterial activity in the MFCs which presumably favored dechlorination of DDE under anaerobic conditions. The reductive dechlorination process requires an electron donor and, in our experiment, it was the naturally occurring soil carbon source or external inputs such as adding compost. Bacteria can use chlorinated molecules (i.e. DDE) not as a source of food, but as a respiration aid and an electron acceptor.

The results of Soil $+D D E$ MFCs suggest that there was an initial selective effect of DDE on the natural soil microbial community and some bacterial populations able to degrade the pesticide were selected. MFCs were effective in promoting the pesticide degradation in the first 60 days in line with the high values of microbial numbers, viability and activity. The fact that at 180 days there was no substantial increase in the DDE removal, could be due to a decrease in the carbon source for bacteria metabolism.

The MFCs added with compost (Soil + DDE + compost) degraded in the first 2 months less DDE, presumably because a fraction of the microbial community was composed by compost bacterial populations not able to degrade the pesticide. However, the compost was an additional carbon source and favored DDE degradation for a longer time. The reductive dechlorination can take place if an appropriate ratio of electron acceptors to donors is present.

After 60 days, several factors can have limited the performance of the MFCs, in addition to the decrease in degradable compounds and electron donors and soil water evaporation (a drastic reduction of water content was observed in all the MFCs). As demonstrated by Zhang et al. [50], water content plays a key role for the proper functioning of this technology. Our MFCs were not well-sealed and a partial water evaporation occurred; this phenomenon could have influenced the anaerobic condition at the anode with a detrimental effect on the bacteria performance. In line with these results, a significant reduction in the power supplied by the MFCs was also observed, showing the connection between the energy production and the bacterial activity.

The overall results suggest that MFCs can be useful in promoting DDE degradation in few days (60 days). In fact, the same soil microbial community in BATCH conditions was able to degrade DDE 12 months after the start of the experiment. This means that the microbial community employed a lot of time to respond to this persistent pesticide.

MFCs are a promising technology in promoting contaminant degradation and the approach of integrating electrical, chemical and microbiological measurements make it possible to show the role of bacterial communities in their performance. However, all factors which can influence cell functioning need to be controlled. DDE degradation is a complex process which can require both anaerobic and aerobic bacterial metabolism. Further microbiological analyses are in progress in order to identify the bacterial populations potentially involved in DDE degradation from Soil $+D D E$ and Soil $+D D E+$ compost MFCs. The use of MFCs for soil recovery from contaminants are of great interest to scientific community but because few works have been performed so far, additional research on persistent contaminants are desirable.

\section{Conclusions}


In this work, a preliminary study on the use of MFCs for promoting DDE soil decontamination is presented. Various experimental conditions (e.g. compost addition and open/closed circuit) were applied for evaluating the performance of MFCs.

The overall results showed that MFCs promoted a substantial DDE removal in 2 months. The compost addition stimulated microbial activity for a longer time allowing to achieve DDE removal percentages at 6 months higher than those obtained in 2 months in Soil + DDE MFCs. The MFC power generation decreased strongly over time, in line with the decrease in microbial abundance, cell viability and microbial activity.

These preliminary results are encouraging, because they demonstrated that, when used as electrolyte for MFC, the soil decontamination process was accelerated, harvesting at the same time energy. The produced power was quite low, nevertheless it was sufficient to charge capacitors able to feed micro-sensors. Furthermore, since the cell activity was dependent on contamination level, the MFC itself can be used as a contaminant sensor.

Further studies under strictly controlled temperature and water content conditions are desirable to fix the best operational conditions for a more effective DDE removal.

\section{Declaration of competing interest}

The authors declare that they have no known competing financial interests or personal relationships that could have appeared to influence the work reported in this paper.

\section{Acknowledgments}

The authors would to thank Elena Sanchez of DIMA, Sapienza University, for her useful support in performing electrical measurements of MFCs. They also thank Claudia Campanale (IRSA-CNR) for her precious help in soil DDE extraction method design.

This research was partially performed in the framework of the "Energy for Taranto- Technology And pRocesses for the Abatement of pollutaNts and the remediation of conTaminated sites with raw materials recovery and production of energy tOtally green (TARANTO)" project, funded by the Ministry of Education, University and Research, grant number ARS01_00637.

\section{References}

The corrections made in this section will be reviewed and approved by a journal production editor. The newly added/removed references and its citations will be reordered and rearranged by the production team.

[1] Busvine J.R. DDT: fifty years for good or ill. Pestic Outlook 1989;1:4-8.

[2] Boul H.L. DDT residues in the environment - a review with a New Zealand perspective. New Zeal J Agric Res 1995;38:257-277. doi:10.1080/00288233.1995.9513126.

[3] Metcalf R.L. Insect Control Technology. Kirk-othmer Encycl. Chem. Technol. Hoboken, NJ, USA: John Wiley \& Sons, Inc.; 2000. doi:10.1002/0471238961.0914190513052003.a01.

[4] Foght J., April T., Biggar K., Aislabie J. Bioremediation of DDT-contaminated soils: a review. Bioremediat J 2001;5:225-246. doi:10.1080/20018891079302. 
[5] Turusov V., Rakitsky V., Tomatis L. Dichlorodiphenyltrichloroethane (DDT): ubiquity, persistence, and risks. Environ Health Perspect 2002;110:125-128. doi:10.1289/ehp.02110125.

[6] Aislabie J.M., Richards N.K., Boul H.L. Microbial degradation of DDT and its residues-a review. New Zeal J Agric Res 1997;40:269-282. doi:10.1080/00288233.1997.9513247.

[7] ATSDR. Public health statement for DDT, DDE, and DDD. Agency for toxic substances and disease registry. Division of Toxicology 2002;9. https://www.atsdr.cdc.gov/phs/phs.asp?id=79\&tid $=20$.

[8] Aigner E.J., Leone A.D., Falconer R.L. Concentrations and enantiomeric ratios of organochlorine pesticides in soils from the U.S. Corn belt. Environ Sci Technol 1998;32:1162-1168. doi:10.1021/es970750h.

[9] Boul H.L., Garnham M.L., Hucker D., Baird D., Aislabie J. Influence of agricultural practices on the levels of DDT and its residues in soil. Environ Sci Technol 1994;28:1397-1402. doi:10.1021/es00057a004.

[10] Strömpl C., Thiele J.H. Comparative fate of 1,1-Diphenylethylene (DPE), 1,1-Dichloro-2,2-bis(4Chlorophenyl)-Ethylene (DDE), and pentachlorophenol (PCP) under alternating aerobic and anaerobic conditions. Arch Environ Contam Toxicol 1997;33:350-356. doi:10.1007/s002449900264.

[11] U.S. Geological Survey. The quality of our nation's waters; nutrients and pesticides. US Geological Survey Circular 1999;1225. doi:10.3133/cir1225.

[12] European Commission. Persistent organic pollutants: towards a POPs-free future. About Sci Environ Policy 2017;19:32. doi:10.2779/170269.

[13] Xia C., Ma X., Liu S., Fan P. Studies on remediation of DDT-contaminated soil and dechlorination of DDT. Procedia Environ Sci 2012;16:289-292. doi:10.1016/j.proenv.2012.10.040.

[14] Thomas J.E., Ou L.-T., Al-Agely A. DDE remediation and degradation. In: Whitacre D.M., editor. Rev. Environ. Contam. Toxicol.. New York, NY: Springer; 2008. p. 55-69. doi:10.1007/978-0387-74816-0_3.

[15] Villa R.D., Trovó A.G., Nogueira R.F.P. Soil remediation using a coupled process: soil washing with surfactant followed by photo-Fenton oxidation. J Hazard Mater 2010;174:770-775. doi:10.1016/j.jhazmat.2009.09.118.

[16] Sudharshan S., Naidu R., Mallavarapu M., Bolan N. DDT remediation in contaminated soils: a review of recent studies. Biodegradation 2012;23:851-863. doi:10.1007/s10532-012-9575-4.

[17] U.S. Environmental Protection Agency (USEPA). Superfund green remediation strategy. 2010.

[18] Faivre N., Fritz M., Freitas T., de Boissezon B., Vandewoestijne S. Nature-Based Solutions in the EU: innovating with nature to address social, economic and environmental challenges. Environ Res 2017;159:509-518. doi:10.1016/j.envres.2017.08.032. 
Gorby Y.A., Yanina S., McLean J.S., Rosso K.M., Moyles D., Dohnalkova A., et al. Electrically conductive bacterial nanowires produced by Shewanella oneidensis strain MR-1 and other microorganisms. Proc Natl Acad Sci U S A 2006; $\underline{103}(\underline{30}) \underline{11358-11363}$. doi:10.1073/pnas.0604517103.

[20] Pisciotta J.M., Dolceamore J.J. Jr. Bioelectrochemical and conventional bioremediation of environmental pollutants. J Microb Biochem Technol 2016;8:327-343. doi:10.4172/19485948.1000306.

[21] Jayabalan T., Matheswaran M., Naina Mohammed S. Biohydrogen production from sugar industry effluents using nickel based electrode materials in microbial electrolysis cell. Int J Hydrogen Energy 2019;44:17381-17388. doi:10.1016/j.ijhydene.2018.09.219.

[22] Santoro C., Arbizzani C., Erable B., Ieropoulos I. Microbial fuel cells: from fundamentals to applications. A review. J Power Sources 2017;356:225-244. doi:10.1016/j.jpowsour.2017.03.109.

[23] Hamelers H.V.M., Ter Heijne A., Sleutels T.H.J.A., Jeremiasse A.W., Strik D.P.B.T.B., Buisman C.J.N. New applications and performance of bioelectrochemical systems. Appl Microbiol Biotechnol 2010;85:1673-1685. doi:10.1007/s00253-009-2357-1.

[24] Bajracharya S., Sharma M., Mohanakrishna G., Dominguez Benneton X., Strik D.P.B.T.B., Sarma P.M., et al. An overview on emerging bioelectrochemical systems (BESs): technology for sustainable electricity, waste remediation, resource recovery, chemical production and beyond. Renew Energy 2016;98:153-170. doi:10.1016/j.renene.2016.03.002.

[25] Weber K.A., Achenbach L.A., Coates J.D. Microorganisms pumping iron: anaerobic microbial iron oxidation and reduction. Nat Rev Microbiol 2006;4:752-764. doi:10.1038/nrmicro1490.

[26] Pisciotta J.M., Zaybak Z., Call D.F., Nam J.-Y., Logan B.E. Enrichment of microbial electrolysis cell biocathodes from sediment microbial fuel cell bioanodes. Appl Environ Microbiol 2012;78:5212-5219. doi:10.1128/AEM.00480-12.

[27] Morris J.M., Jin S., Crimi B., Pruden A. Microbial fuel cell in enhancing anaerobic biodegradation of diesel. Chem Eng J 2009;146:161-167. doi:10.1016/j.cej.2008.05.028.

[28] Pham H., Boon N., Marzorati M., Verstraete W. Enhanced removal of 1,2-dichloroethane by anodophilic microbial consortia. Water Res 2009;43:2936-2946. doi:10.1016/j.watres.2009.04.004.

[29] Huang D.-Y., Zhou S.-G., Chen Q., Zhao B., Yuan Y., Zhuang L. Enhanced anaerobic degradation of organic pollutants in a soil microbial fuel cell. Chem Eng J 2011;172:647-653. doi:10.1016/j.cej.2011.06.024.

[30] Huang L., Chai X., Quan X., Logan B.E., Chen G. Reductive dechlorination and mineralization of pentachlorophenol in biocathode microbial fuel cells. Bioresour Technol 2012;111:167-174. doi:10.1016/j.biortech.2012.01.171.

[31] Morris J.M., Jin S. Enhanced biodegradation of hydrocarbon-contaminated sediments using microbial fuel cells. J Hazard Mater 2012;213-214:474-477. doi:10.1016/j.jhazmat.2012.02.029. 
[32] Chun C.L., Payne R.B., Sowers K.R., May H.D. Electrical stimulation of microbial PCB degradation in sediment. Water Res 2013;47:141-152. doi:10.1016/j.watres.2012.09.038.

[33] Kong F., Wang A., Ren H.-Y. Improved 4-chlorophenol dechlorination at biocathode in bioelectrochemical system using optimized modular cathode design with composite stainless steel and carbon-based materials. Bioresour Technol 2014;166:252-258. doi:10.1016/j.biortech.2014.05.049.

[34] Lai A., Verdini R., Aulenta F., Majone M. Influence of nitrate and sulfate reduction in the bioelectrochemically assisted dechlorination of cis-DCE. Chemosphere 2015;125:147-154. doi:10.1016/j.chemosphere.2014.12.023.

[35] Lai A., Aulenta F., Mingazzini M., Palumbo M.T., Papini M.P., Verdini R., et al. Bioelectrochemical approach for reductive and oxidative dechlorination of chlorinated aliphatic hydrocarbons (CAHs). 2017;169:351-360. doi:10.1016/j.chemosphere.2016.11.072.

[36] Leitão P., Rossetti S., Nouws H.P.A., Danko A.S., Majone M., Aulenta F. Bioelectrochemicallyassisted reductive dechlorination of 1,2-dichloroethane by a Dehalococcoides- enriched microbial culture. Bioresour Technol 2015;195:78-82. doi:10.1016/j.biortech.2015.06.027.

[37] Wu Q., Jiao S., Ma M., Peng S. Microbial fuel cell system: a promising technology for pollutant removal and environmental remediation. Environ Sci Pollut Res 2020;27:6749-6764. doi:10.1007/s11356-020-07745-0.

[38] Barra Caracciolo A., Donato De G., Finizio A., Grenni P., Santoro S., Petrangeli A.B. A new online database on chemicals in accordance with REACH regulation. Hum Ecol Risk Assess An Int J 2013;19:1682-1699. doi:10.1080/10807039.2012.708271.

[39] Frattini D., Falcucci G., Minutillo M., Ferone C., Cioffi R., Jannelli E. On the effect of different configurations in air-cathode MFCs fed by composite food waste for energy harvesting. Chem Eng Trans 2016;49:85-90. doi:10.3303/CET1649015.

[40] Karra U., Manickam S.S., McCutcheon J.R., Patel N., Li B. Power generation and organics removal from wastewater using activated carbon nanofiber (ACNF) microbial fuel cells (MFCs). Int J Hydrogen Energy 2013;38:1588-1597. doi:10.1016/j.ijhydene.2012.11.005.

[41] Cao X., Song H., Yu C., Li X. Simultaneous degradation of toxic refractory organic pesticide and bioelectricity generation using a soil microbial fuel cell. Bioresour Technol 2015;189:87-93. doi:10.1016/j.biortech.2015.03.148.

[42] Guan C.-Y., Tseng Y.-H., Tsang D.C.W., Hu A., Yu C.-P. Wetland plant microbial fuel cells for remediation of hexavalent chromium contaminated soils and electricity production. J Hazard Mater 2019;365:137-145. doi:10.1016/j.jhazmat.2018.10.086.

[43] Song N., Jiang H.-L. Effects of initial sediment properties on start-up times for sediment microbial fuel cells. Int J Hydrogen Energy 2018;43:10082-10093. doi:10.1016/j.ijhydene.2018.04.082. 
Gajda I., Stinchcombe A., Greenman J., Melhuish C., Ieropoulos I. Microbial fuel cell - a novel self-powered wastewater electrolyser for electrocoagulation of heavy metals. Int J Hydrogen Energy 2017;42:1813-1819. doi:10.1016/j.ijhydene.2016.06.161.

[45] Liu H., Zhang B., Liu Y., Wang Z., Hao L. Continuous bioelectricity generation with simultaneous sulfide and organics removals in an anaerobic baffled stacking microbial fuel cell. Int J Hydrogen Energy 2015;40:8128-8136. doi:10.1016/j.ijhydene.2015.04.103.

[46] Zhang B., Zhang J., Liu Y., Hao C., Tian C., Feng C., et al. Identification of removal principles and involved bacteria in microbial fuel cells for sulfide removal and electricity generation. Int $\mathrm{J}$ Hydrogen Energy 2013;38:14348-14355. doi:10.1016/j.jhydene.2013.08.131.

[47] Ancona V., Barra Caracciolo A., Grenni P., Di Lenola M., Campanale C., Calabrese A., et al. Plant-assisted bioremediation of a historically PCB and heavy metal-contaminated area in Southern Italy. N Biotechnol 2017;38:65-73. doi:10.1016/j.nbt.2016.09.006.

[48] Di Lenola M., Barra Caracciolo A., Grenni P., Ancona V., Rauseo J., Laudicina V.A., et al. Effects of apirolio addition and alfalfa and compost treatments on the natural microbial community of a historically PCB-contaminated soil. Water, air. Soil Pollut 2018;229:143. doi:10.1007/s11270018-3803-4.

[49] Papaharalabos G., Greenman J., Melhuish C., Ieropoulos I. A novel small scale Microbial Fuel Cell design for increased electricity generation and waste water treatment. Int J Hydrogen Energy 2015;40:4263-4268. doi:10.1016/j.ijhydene.2015.01.117.

[50] Zhang D., Ge Y., Wang W. Study of a terrestrial microbial fuel cell and the effects of its power generation performance by environmental factors. Proc. 2013 Int. Conf. Adv. Mechatron. Syst.. IEEE; 2013. p. 445-448. doi:10.1109/ICAMechS.2013.6681825.

[51] Barra Caracciolo A., Grenni P., Cupo C., Rossetti S. In situ analysis of native microbial communities in complex samples with high particulate loads. FEMS Microbiol Lett 2005;253:5558. doi:10.1016/j.femsle.2005.09.018.

[52] Grenni P., Rodríguez-Cruz M.S., Herrero-Hernández E., Marín-Benito J.M., Sánchez-Martín M.J., Barra Caracciolo A. Effects of wood amendments on the degradation of terbuthylazine and on soil microbial community activity in a clay loam soil. Water, air. Soil Pollut 2012;223:5401-5412. doi:10.1007/s11270-012-1289-z.

[53] Barra Caracciolo A., Bustamante M.A., Nogues I., Di Lenola M., Luprano M.L., Grenni P. Changes in microbial community structure and functioning of a semiarid soil due to the use of anaerobic digestate derived composts and rosemary plants. Geoderma 2015;245-246:89-97. doi:10.1016/j.geoderma.2015.01.021.

[54] Grenni P., Barra Caracciolo A., Rodríguez-Cruz M.S., Sánchez-Martín M.J. Changes in the microbial activity in a soil amended with oak and pine residues and treated with linuron herbicide. Appl Soil Ecol 2009;41:2-7. doi:10.1016/j.apsoil.2008.07.006.

[55] Ahuja R., Awasthi N., Manickam N., Kumar A. Metabolism of 1,1-dichloro-2,2-bis(4chlorophenyl)ethylene by Alcaligenes denitrificans. Biotechnol Lett 2001;23. 
[56] Huang H.-J., Liu S.-M., Kuo C.-E. Anaerobic biodegradation of DDT residues (DDT, DDD, and DDE) in estuarine sediment. J Environ Sci Heal Part B 2001;36:273-288. doi:10.1081/PFC100103569.

[57] Kantachote D., Singleton I., Naidu R., McClure N., Megharaj M. Sodium application enhances DDT transformation in a long-term contaminated soil. Water. air. Soil Pollut 2004:154:115-125.

\section{Highlights}

- MFCs showed significant capacity in removing DDE at 2 months of testing.

- Compost addition in MFC stimulated soil microbial activity favouring DDE removal for a longer time.

- MFC power generation decreased over time, in line with a decrease in microbial abundance and activity.

\section{Queries and Answers}

Query: Your article is registered as belonging to the Special Issue/Collection entitled "SDEWES 2019 (Kovac)". If this is NOT correct and your article is a regular item or belongs to a different Special Issue please contact d.norman@elsevier.com immediately prior to returning your corrections.

Answer: Yes

Query: Please confirm that given names and surnames have been identified correctly and are presented in the desired order and please carefully verify the spelling of all authors' names.

Answer: Please, we have corrected the surname of the last author as follows: Barra Caracciolo.

Query: Have we correctly interpreted the following funding source(s) and country names you cited in your article: Ministry of Education, University and Research, Italy?

Answer: Yes

Query: Please provide the volume number or issue number or page range or article number for the bibliography in Ref(s). [19].

Answer: ok, I have provided the information required

Query: Highlights should only consist of 85 characters per bullet point, including spaces. The highlights provided are too long; please edit them to meet the requirement.

Answer: We have shortened the highlights as follows: 
- MFCs showed significant capacity in removing DDE at 2 months of testing

- Compost in MFC stimulated microbial activity favouring DDE removal for a longer time

- MFC power generation and microbial abundance and activity decreased over time 